\title{
ATIVIDADE DE ENZIMAS RELACIONADAS COMA MOBILIZAÇÃO DE CARBOIDRATOS DURANTE A DORMÊNCIA DA NOGUEIRA (Juglans Regia) ${ }^{1}$
}

\author{
IDEMIR CITADIN ${ }^{2}$, AGNÈS GUILLIOT ${ }^{3}$, MARC BONHOMME ${ }^{4}$, RÉMY RAGEAU $^{4}$
}

RESUMO - A brotação da nogueira é dependente da mobilização de carboidratos do lenho para as gemas localizadas na porção superior dos ramos. O objetivo do trabalho foi contribuir para o entendimento do mecanismo de brotação acrótona da nogueira, em clima temperado, através da mensuração da atividade da $\alpha$-amilase (EC 3.2.1.1) e sacarose fosfato sintase (SPS - EC 2.4.1.14) relacionadas com a mobilização de carboidratos, durante o período de dormência. Para cada coleta, foram amostrados cinco ramos do ano, durante os meses de setembro a março. Em abril, próximo à retomada do crescimento ativo, foram feitas três amostragens. As partes apical, subapical e da base dos ramos foram separadas em casca, lenho (xilema) e gemas. O tempo médio de brotação (TMB) em condições controladas $\left(25^{\circ} \mathrm{C}\right)$, a umidade ponderal e a atividade das enzimas acima relacionadas foram determinadas. Os resultados obtidos reforçam a teoria de que o gradiente de brotação na nogueira se desenvolve durante a ecodormência e apresenta uma relação de dependência com a atividade da á-amilase; não está evidente a relação da atividade da SPS com a evolução do crescimento das gemas, durante a ecodormência.

Termos para indexação: $\alpha$-amilase, sacarose fosfato sintase, Juglans regia.

\section{WALNUT ENZYME ACTIVITY RELATED WITH CARBOHYDRATE MOBILIZATION DURING DORMANCY PERIOD}

\begin{abstract}
Juglans regia L. sprout depends on the carbohydrate mobilization from the parenchyma cells into the buds located in the upper portion of the twigs. The objective of this work was to contribute to the walnut tree sprout acrotony mechanism, in temperate climate, through the activity of alpha-amylase (EC 3.2.1.1), and Sucrose Phosphate Synthase (SPS - EC 2.4.1.14) mensuration, related to carbohydrate mobilization, during the dormancy period. From September to March, five one-year-old twigs were monthly sampled around. In April, close to budbreak, three samples were accomplished. The twigs were divided in apical, sub-apical, and base, and separated in bark, buds and wood (xylem). The average time of bud break in controlled conditions $\left(25^{\circ} \mathrm{C}\right)$, water content, and activity of the above mentioned enzymes were determined. The results showed that the sprout gradient develops itself during ecodormancy period, and it is related with the alpha-amylase activity; the relationship of the SPS activity with this gradient is not evident.
\end{abstract} Index Terms: alpha-amylase, sucrose phosphate synthase, Juglans regia.

\section{INTRODUÇÃO}

Juglans regia L., conhecida como nogueira, nogueira-inglesa ou nogueira-da-Pérsia, é a espécie economicamente mais importante e lidera a produção de nozes no mundo (McGranahan \& Leslie, 1990). A produção mundial está em torno de 700.000 toneladas. A China lidera a produção mundial (260.000 ton), seguida dos EUA (254.000 ton.) e Turquia (70.000 ton). Na Europa, os principais países produtores são a França (23.000 ton.) e a Itália (18.000 ton.). Na América do Sul, o Chile é o maior produtor com cerca de 12.000 toneladas, sendo que destas, 10.000 ton. são exportadas (USDA, 1999). A maioria das cultivares necessitam acima de 800 horas de frio abaixo de $7^{\circ} \mathrm{C}$, durante o inverno, para superar a dormência (Sibbett e Osgood, 1985), o que limita seu cultivo a países ou regiões de clima temperado. Nesse sentido, essa espécie não é produzida comercialmente no Brasil, pois não apresenta condições climáticas satisfatórias para seu

\footnotetext{
${ }^{1}$ (Trabalho 147-08). Recebido em:10-06-2008. Aceito para publicação em: 20-01-2009.

${ }^{2}$ Universidade Tecnológica Federal do Paraná, Via do Conhecimento, Km 01, Cx. Postal 571, 85501-970, Pato Branco, Paraná. E-mail: idemir@utfpr.edu.br ;

${ }^{3}$ UMR PIAF (Université Blaise Pascal), Les Cézeaux, 24 avenue des Landais 63177 Aubière - France. E-mail: Agnes.GUILLIOT@piaf.univ-bpclermont.fr

${ }^{4}$ UMR PIAF (INRA-Univ. Blaise Pascal), Site INRA de Crouël, 234 Av. du Brezet, 63100 Clermont-Ferrand - France. Email: bonhomme@clermont.inra.fr, rageau@clermont.inra.fr
} 
desenvolvimento. No entanto, o estudo dos mecanismos envolvidos na brotação e ramificação de espécies altamente exigentes em frio é fundamental para se entender os problemas decorrentes quando essas espécies são submetidas a condições de clima subtropical, não adequado aos seus cultivos.

A ramificação é um mecanismo dependente da capacidade de brotação de cada uma das gemas localizadas no ramo. Nas espécies de ramificação acrótona, observa-se o desenvolvimento, na saída do inverno, das gemas situadas no ápice dos ramos. Ao contrário, nas espécies de ramificação basítona, a brotação ocorre nas gemas da base dos ramos.

O determinismo da acrotonia e da basitonia é, ainda, mal entendido. Seus conceitos foram propostos por Champagnat (1965) e revistos por Crabbé (1987), porém os seus mecanismos de controle têm sido pouco explorados.

As modalidades de brotação na primavera são o resultado da evolução dos gradientes ao longo do ramo, no qual se localizam essas gemas, e da condição própria de cada gema, que, por sua vez, é o reflexo da capacidade intrínseca de crescimento e da evolução do crescimento antes da brotação (Brunel, 2001; Leite, 2004). Este segundo parâmetro está associado ao primeiro pela saída da endodormência. Suspeitase que os gradientes de brotação têm origem nos gradientes da saída da endodormência, que se formam ao longo do ramo. Porém, esses gradientes não são observados em árvores localizadas em condições de clima temperado (Mauget \& Rageau, 1997). Nessas condições de clima, durante o período máximo de endodormência, a capacidade de brotação das gemas da base do ramo é maior que as situadas no ápice dos ramos. Quando ocorre acúmulo suficiente de frio, o gradiente basítono tende a desaparecer durante a saída da endodormência e, na ecodormência, ele é substituído pela acrotonia.

A acrotonia, enquanto propriedade fisiológica fundamental dos ramos (Champagnat, 1989), deve ser elucidada. Para isso, tem sido pesquisada a origem dos gradientes de crescimento que ocorrem antes da brotação, agrupados à posição do ramo. Contudo, as bases bioquímicas e/ou fisiológicas dos fatores causadores da acrotonia são ainda hipotéticas, pois as abordagens experimentais focadas nos gradientes são pouco desenvolvidas. Alguns estudos relativos aos gradientes de brotação abordaram as bases tróficas (Brunel, 2001; Leite, 2004; Alves et al., 2007; Decourteix et al., 2008), os hormônios (Crabbé, 1987) e o estado hídrico (Leite, 2004).

Referente às bases tróficas, sabe-se também que o parênquima do xilema está relacionado com a reserva, mobilização e translocação de carboidratos. A mobilização de açúcares, a partir das reservas de amido, visa a aumentar a quantidade de açúcares solúveis potencialmente utilizáveis para 0 metabolismo celular. Essa mobilização foi estudada na nogueira por Améglio et al. (2001) e Lacointe et al. (2001).

Existe uma relação linear entre a diminuição da temperatura exterior (ambiental) e a diminuição do amido armazenado no parênquima do xilema dos ramos de Populus sp. A natureza dos açúcares liberados após a exposição de ramos de Populus $s p$. ao frio permitiu mostrar que é essencialmente a $\alpha-$ amilase (EC 3.2.1.1) a enzima responsável pela hidrólise do amido à baixa temperatura (Sauter, 1988; Witt \& Sauter, 1994; Sauter et al., 1998; Elle e Sauter, 2000). As baixas temperaturas $\left(0,5^{\circ} \mathrm{C}\right)$ induzem a expressão e a atividade de $\alpha$-amilase na macieira (Wegrzyn et al., 2000). Observou-se, também, que as partes apicais do ramo de nogueira apresentam uma atividade da $\alpha$-amilase superior às porções basais (Lefrève, 2002).

A principal forma transportada de açúcar nos vegetais superiores é a sacarose (Roitsch, 1999). A enzima que sintetiza a sacarose é a sacarose fosfato sintase (SPS: EC 2.4.1.14) e desempenha um papel preponderante na mobilização de reservas glicídicas. A SPS participa da converção de UDP-Glicose e frutose em sacarose. Na nogueira, durante o inverno, a sacarose é a principal forma de açúcar transportado na seiva do xilema, podendo ser utilizada como marcador potencial da mobilização de açúcares para a reparação da embolia hibernal (ocasionada pelo congelamento) ou para a retomada do crescimento ativo (Améglio et al., 2000).

O objetivo do trabalho foi contribuir para a determinação do mecanismo de brotação acrótona da nogueira, em clima temperado, através da mensuração da atividade, ao longo do ramo, da alfaamilase e SPS, relacionadas com a mobilização de carboidratos e, por consequência, com a disponibilidade de açucares para gemas, durante o período de dormência e antes da brotaçao.

\section{MATERIAL E MÉTODOS}

O experimento foi conduzido na Unidade Mista de Pesquisa em Fisiologia Integrada de Árvores Frutíferas e Florestais (UMR/PIAF) da Universidade Blaise Pascal e do Instituto Nacional de Pesquisa Agricola (INRA), em Clermont-Ferrand, França, de setembro de 2003 a abril de 2004.

Para atingir o objetivo proposto, foram estudados alguns parâmetros: 
- natureza e intensidade do estado da dormência e estado hídrico das gemas, via umidade ponderal;

- estado hídrico dos tecidos do ramo e atividade de enzimas do metabolismo do carbono ligadas à mobilização de reservas amiláceas $(\alpha-$ amilase e SPS).

Tais parâmetros permitiram perceber a evolução, do repouso até a brotação, dos gradientes ao longo do ramo, das condições das gemas e dos tecidos do ramo e, por consequência, a disponibilidade de açúcares utilizáveis para o desenvolvimento das gemas antes da brotação e para a brotação propriamente dita.

\section{a. Material vegetal}

As amostras foram coletadas de plantas de nogueira (Juglans regia L. cv Franquette), com 9 anos, obtidas por enxertia e cultivadas em pomar sob condições naturais. Para cada coleta, foram amostrados mensalmente cinco ramos do ano, durante os meses de setembro a março. Em abril, próximo à retomada do crescimento ativo, foram realizadas três amostragens. As partes apical, subapical e da base dos ramos foram separadas em casca, lenho (xilema) e gemas.

Amostras do lenho das partes apical, subapical e da base dos ramos foram imediatamente imersas, separadamente, em nitrogênio líquido e, em seguida, mantido a $-80^{\circ} \mathrm{C}$ até a quantificação enzimática.

A brotação das primeiras gemas apicais foi observada em 26 de abril de 2004.

Os resultados expressam a média de cinco ramos amostrados com seus respectivos desviospadrão.

\section{b. Evolução do estado de dormência das gemas}

A fim de caracterizar o estado de dormência das gemas e, em particular, a transição da endodormência para ecodormência, foi empregada metodologia de 'estacas de uma só gema' (Rageau, 1978). Para cada data de coleta, amostras das porções apicais, subapicais e basais dos ramos foram submetidas a $25^{\circ} \mathrm{C}\left( \pm 1^{\circ} \mathrm{C}\right)$ e alta umidade, em câmara de crescimento. $\mathrm{O}$ tempo individual decorrido desde a colocação na câmara até a brotação foi registrado, e a média destes constituiu o tempo médio de brotação (TMB). tecidos

c. Evolução do estado de hidratação dos

A fim de verificar se o aumento da atividade metabólica não está somente relacionada com uma reidratação dos tecidos, uma segunda amostragem das porções apicais, subapicais e basais dos ramos, subdivididas em lenho, casca e gemas, foi utilizada para determinar a quantidade de água dos tecidos (umidade ponderal). Inicialmente, foi mensurada a massa fresca (MF) das amostras. Após, essas amostras foram completamente desidratadas em estufa a $60^{\circ} \mathrm{C}$ para registro da massa seca (MS). A umidade ponderal (UP) foi determinada segundo a fórmula seguinte: $\mathrm{UP}=(\mathrm{MF}-\mathrm{MS}) / \mathrm{MS}$. As médias foram calculadas separadamente para cada data de coleta, tecido e posição do ramo.

\section{d. Atividade de enzimas relacionadas com o} metabolismos de carboidratos.

Para a extração de proteínas solúveis totais, uma amostra de $150 \mathrm{mg}$ de lenho foi triturada em almofaris, em nitrogênio líquido, e acrescida $10 \%$ p/p de polivinil polipirolidona (PVPP). Na amostra triturada, foi acrescido $800 \mathrm{~mL}$ de tampão de extração (HEPES pH 7.0 / KOH, DTT 10 mM, MgCl 5 mM, EDTA $1 \mathrm{mM}$ ) e mantidos em banho de gelo. Após, as amostras foram centrifugadas a $13.000 \mathrm{rpm}$, durante $10 \mathrm{~min}$ a $4{ }^{\circ} \mathrm{C}$. O sobrenadante foi recuperado para as dosagens de á-amilase (Kit Ceralpha - Megazyme) e SPS (Hauch \& Magel, 1998; Schrader \& Sauter, 2002). O kit Ceralpha consiste em adicionar ao estrato contendo $\alpha$-amilase um substrato específico (o $p$ nitrofenil maltoheptaoside, BPNPG7) em presença de um excesso de $\alpha$-glucosidase termoestável. Este substrato, em reação com a $\alpha$-amilase, resulta em $p$ nitrofenil maltossacarídeo que, por sua vez, reage com $\alpha$-glucosidase, resultando em glicose e $p$-nitrofenol, cuja liberação é observada pela formação de uma coloração amarela facilmente quantificada a $400 \mathrm{~nm}$. As médias e os desvios-padrão foram calculados separadamente para cada data de coleta, tecido e posição do ramo. As proteínas totais de cada extrato foram dosadas segundo o método de Bradford (Bradford, 1976). Os resultados da atividade da $\alpha$ amilase foram expressos em $\mu$ mol de $p$-nitrofenol formado por minuto e por miligrama de proteínas totais $\left(\mu \mathrm{mol} . \mathrm{min}^{-1} \cdot \mathrm{mg}^{-1}\right.$ ou U. $\left.\mathrm{mg}^{-1}\right)$. Os resultados da atividade da SPS foram expressos em $\mu$ mol de NADH consumido por minuto, por miligrama de proteínas totais $\left(\mu \mathrm{mol} . \mathrm{min}^{-1} . \mathrm{mg}^{-1}\right.$ ou U. $\left.\mathrm{mg}^{-1}\right)$.

\section{RESULTADOS E DISCUSSÃO}

Na Figura 1, é observado o tempo médio de brotação (TMB) das gemas apicais, subapicais e basais dos ramos. Para o conjunto de gemas, independentemente da localização no ramo, de meados de setembro a meados de novembro, o tempo médio de brotação aumenta de 30 (720 horas) a cerca de 60 dias (1.440 horas): é o período de aumento da intensidade de endodormência. O valor máximo do 
TMB representa a máxima profundidade da endodormência. Observa-se, em seguida, uma queda no TMB até 20 dias (420 horas), em meados de janeiro: é a saída da endodormência. Deste período até a brotação (abril), o TMB diminui lentamente. Estes resultados corroboram os resultados obtidos por Mauget (1982), que demonstrou que, de janeiro a abril (início da brotação), as plantas de nogueira da cultivar Franquette apresentam um TMB baixo, que diminui mais lentamente que no período anterior. Trata-se da pós-dormência ou ecodormência, que se caracteriza, não mais pela necessidade de frio das gemas, mas pela necessidade de calor.

Durante a endodormência, a capacidade de crescimento das gemas da base é maior (TMB mais baixo) que para as gemas subapicais (Mauget, 1984). No entanto, não foi possível observar essa diferença neste experimento, conforme pode ser observado pelos dados obtidos de TMB (Figura 1). Observa-se que, para as gemas apicais, a capacidade de crescimento durante esse período é maior que para as duas categorias anteriores. Não foram encontrados registros bibliográficos concernentes às gemas apicais, porém os registros apresentados na Figura 1 corroboram os dados não publicados registrados na UMR/PIAF do INRA.

A partir de janeiro (período de ecodormência), os TMBs das gemas apicais apresentam-se mais elevados que aqueles das gemas subapicais e basais, até março. Após essa data, observa-se uma inversão rápida. O gradiente dos valores de TMB na coleta de 21 de abril é coerente com o gradiente acrótono de brotação, observado no pomar após alguns dias.

A umidade ponderal é menos variável na casca que no lenho, considerando as diferentes posições no ramo (Figuras 2B e 2C). No lenho, as diferenças são mais expressivas nos meses de setembro a novembro (Figuras 2C). Após esse período, verifica-se uma homogeneidade da umidade ponderal entre as diferentes posições do ramo, tanto para lenho como para casca. A umidade ponderal tende a diminuir até dezembro para lenho, casca e gemas; após esse período, há uma estabilidade que segue até uma data, próxima à brotação, variável segundo o tecido. Em gemas apicais e subapicais, observa-se uma reidratação desde o início de abril, inicialmente fraca e depois muito forte, entre 21 e 28 de abril (Figura 2A). Observa-se que não ocorre reidratação das gemas da base. A reidratação ocorre, então, somente nas gemas que vão efetivamente brotar, e tem início, em geral, um mês antes da brotação. Já no xilema (lenho) e na casca, a reidratção é igualmente fraca, para todas as partes do ramo.

A redução do conteúdo de água coincide com a intensificação da endodormência, que pode ser observada pelo aumento do tempo médio de brotação (TMB) no mesmo período. Após janeiro, quando o TMB se reduz, indicando a saída da endodormência, ocorre estabilização no conteúdo de água dos tecidos (Figuras 1 e 2).

A relação TMB e UP permite dizer que a aceleração do crescimento das gemas apicais e subapicais, manifestado a partir do início de abril pela queda dos valores do TMB, é paralela ao aumento da UP destas gemas, mas essa não antecipa a queda dos valores do TMB. Da mesma maneira, a dinâmica de reidratação do lenho e da casca nas diversas posições do ramo não antecipa a aceleração do crescimento das gemas nos níveis correspondentes.

Durante o início do outono (setembro), a atividade da alfa-amilase solúvel do lenho é igual para as diferentes porções do ramo (apical, subapical e base). No entanto, à medida que a dormência evolui, a atividade dessa enzima nas zonas apical e subapical evolui paralelamente (de setembro a abril), porém mais forte que a atividade encontrada na base dos ramos (Figura 3A). Esse aumento na atividade da alfa-amilase não é consequência de uma reidratação de tecidos, conforme pode ser confirmado na Figura 2, visto que a reidratação só ocorre na última semana de abril. Lefèvre (2002) encontrou que a atividade da alfa-amilase solúvel da zona apical é superior àquela da zona basal, com um pico de atividade que precedia o momento da brotação. Interpreta-se essa diferença como uma maior capacidade de degradação de amido na parte apical do ramo, quando comparado com a base desse mesmo ramo. Isso significa que a capacidade de mobilização de reservas amiláceas é mais intensa na parte apical do ramo e pode estar relacionada com o mecanismo acropetal (brotação das gemas da porção apical) de ramificação dos ramos de nogueira. A mobilização outono-invernal é descrita na literatura como um mecanismo de resistência ao frio (Améglio et al., 2001).

Por outro lado, a atividade da SPS varia pouco de setembro a janeiro, entre as diferentes porções do ramo (Figura 3B). Porém, após o final de dezembro, observa-se uma tendência de decréscimo da atividade da SPS no ápice do ramo e a partir de meados de fevereiro para os níveis subapicais. Por outro lado, a tendência de aumento da atividade da SPS da base do ramo não foi significativa (vide barra de erros) e deve ser considerada. Apesar disso, aceita-se a hipótese de que a capacidade de formação de sacarose e de sua exportação através do apoplasto é maior na base dos ramos à medida 
que se aproxima da brotação. Isso coincide com o aumento da atividade da $\alpha$-amilase. Possivelmente essa sacarose está sendo drenada para o ápice dos ramos, local de maior hidratação (Figura 2A e 2B) e onde ocorre a brotação das gemas. Assim, o amido que é degrado na base, é rapidamente convertido em sacarose pela ação da SPS e transportado para o ápice dos ramos. A diminuição da atividade da SPS, em nível apical do ramo, pode ser interpretada como uma diminuição da capacidade de exportação de sacarose, pelo fato de ocorrer aumento no consumo de açúcares, para atender à demanda da retomada metabólica local. Isso significa que a capacidade de mobilização de açúcares solúveis é maior na porção apical dos ramos e pode estar ligada com o mecanismo acropetal de brotação.

Schrader \& Sauter (2002) encontraram em Populus sp. que a atividade da SPS aumenta no outono, sendo máxima no inverno durante a conversão de amido em açúcares solúveis e cai na primavera durante a ressíntese do amido. No xilema, durante o verão, a atividade da SPS permanece muito baixa. Nos ramos de Populus, Salix, Acer e Fagus, condicionados a $-5^{\circ} \mathrm{C}$ e $10^{\circ} \mathrm{C}$, Schrader \& Sauter (2002) mostraram que a atividade da SPS aumenta em ramos submetidos à temperatura mais baixa.

Esses resultados foram obtidos em vegetais lenhosos de clima temperado, com alta necessidade de frio, nos seus locais de origem, ou seja, em condições de inverno rigoroso, com temperaturas negativas e baixa flutuação térmica. Questiona-se como seria a mobilização das reservas de frutíferas de clima temperado, especialmente macieira, pereira e pessegueiro, quando submetidas a condições de clima subtropical. Sugere-se a hipótese de que ocorra uma alteração muito grande no metabolismo e transporte de açúcares dos tecidos 'fontes' (parênquima do xilema) para os tecidos 'drenos' (gemas), ocasionada pela falta de frio e pela flutuação de temperatura durante a endodormência. Assim, um deficiente fornecimento de açúcares para as gemas causaria a necrose das mesmas ou o desenvolvimento irregular, floração e brotação desuniformes e gemas fracas, que produzirão frutos igualmente fracos.

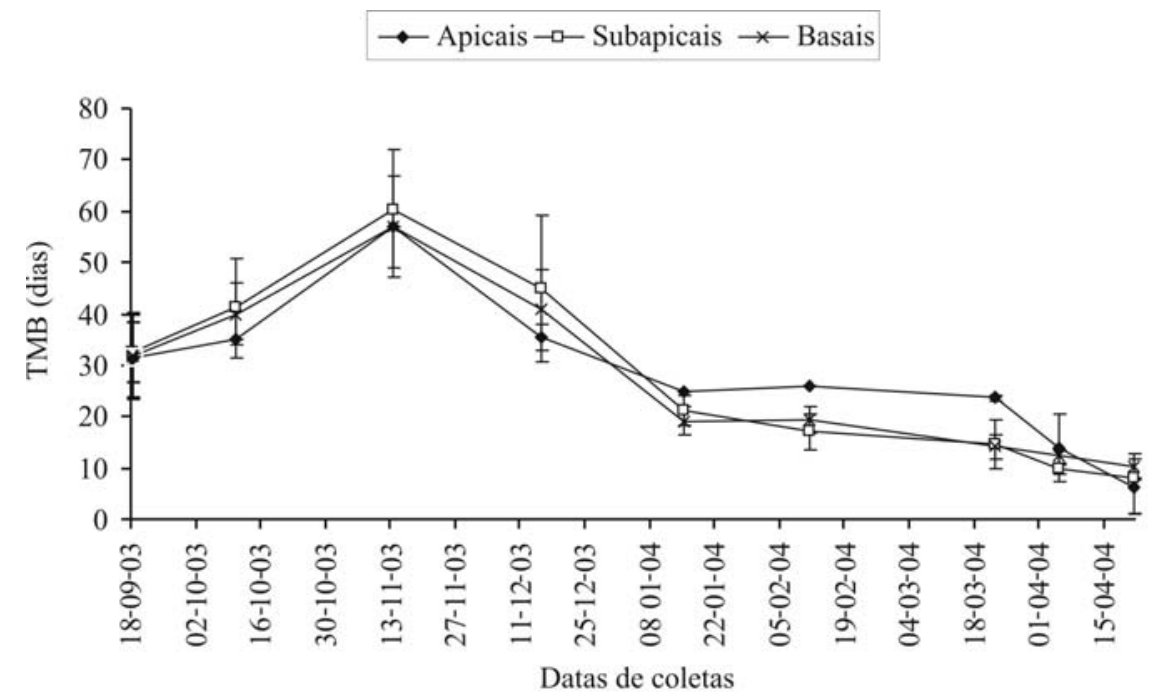

FIGURA 1- Tempo médio de brotação (TMB), a $25^{\circ} \mathrm{C}$, de gemas de nogueira (Juglans regia cv. Franquette), localizadas em três posições do ramo (gemas apicais, subapicais e basais), durante o repouso (setembro a abril). As barras indicam o desvio-padrão do TMB. UMR/PIAF - ClermontFerrand, 2004. 
A

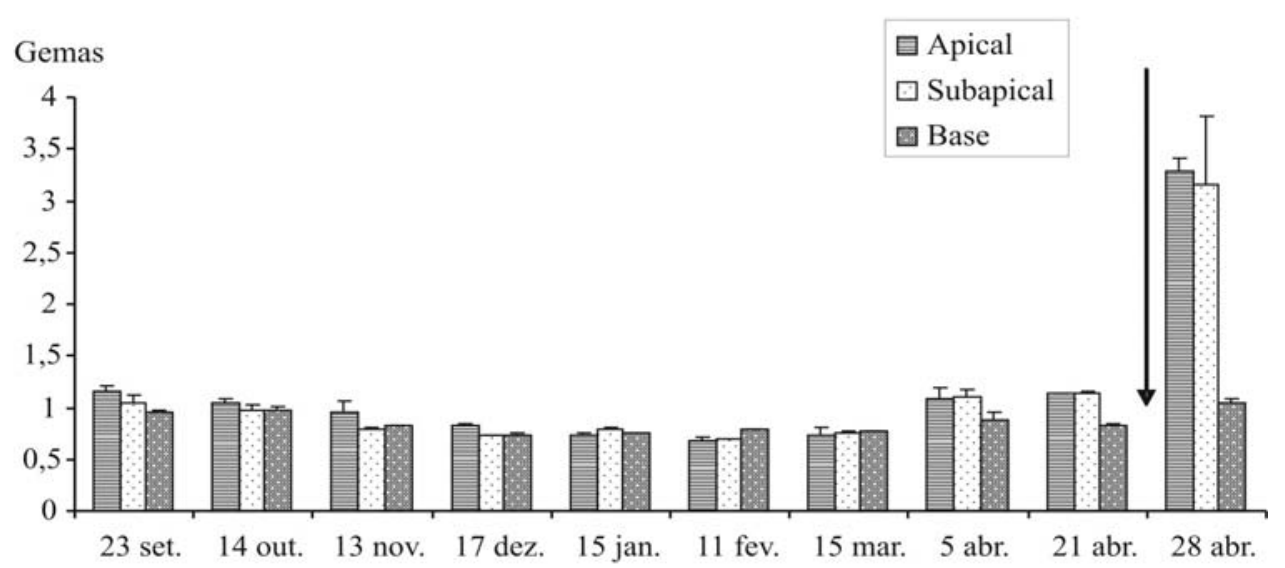

B

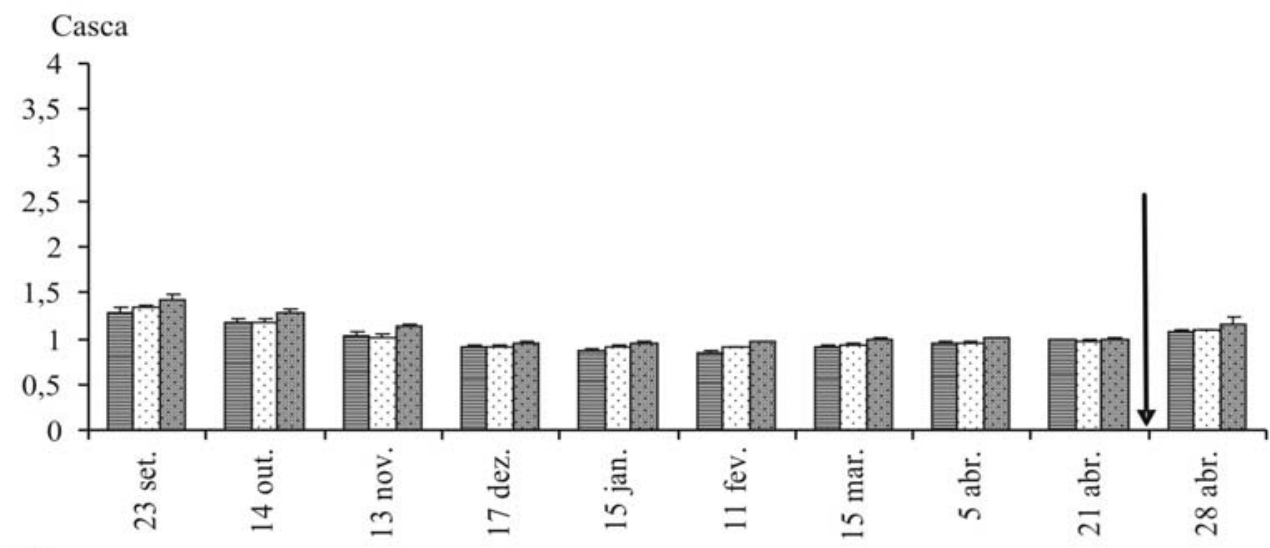

C

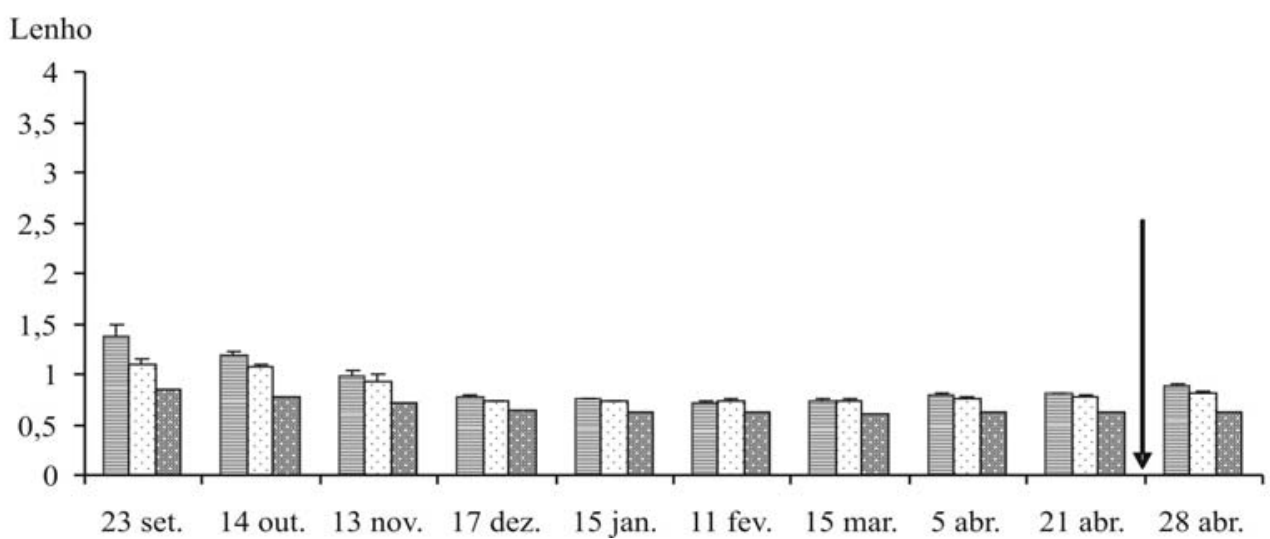

FIGURA 2 - Umidade ponderal para gemas (A), casca (B) e lenho (xilema) (C) de nogueira (Juglans regia cv. Franquette), em três posições do ramo (Apical; Subapical; Base), durante os meses de setembro de 2003 abril de 2004. As barras indicam o desvio-padrão, e a seta, a data da primeira brotação (26-04). UMR/PIAF - Clermont-Ferrand, 2004. 


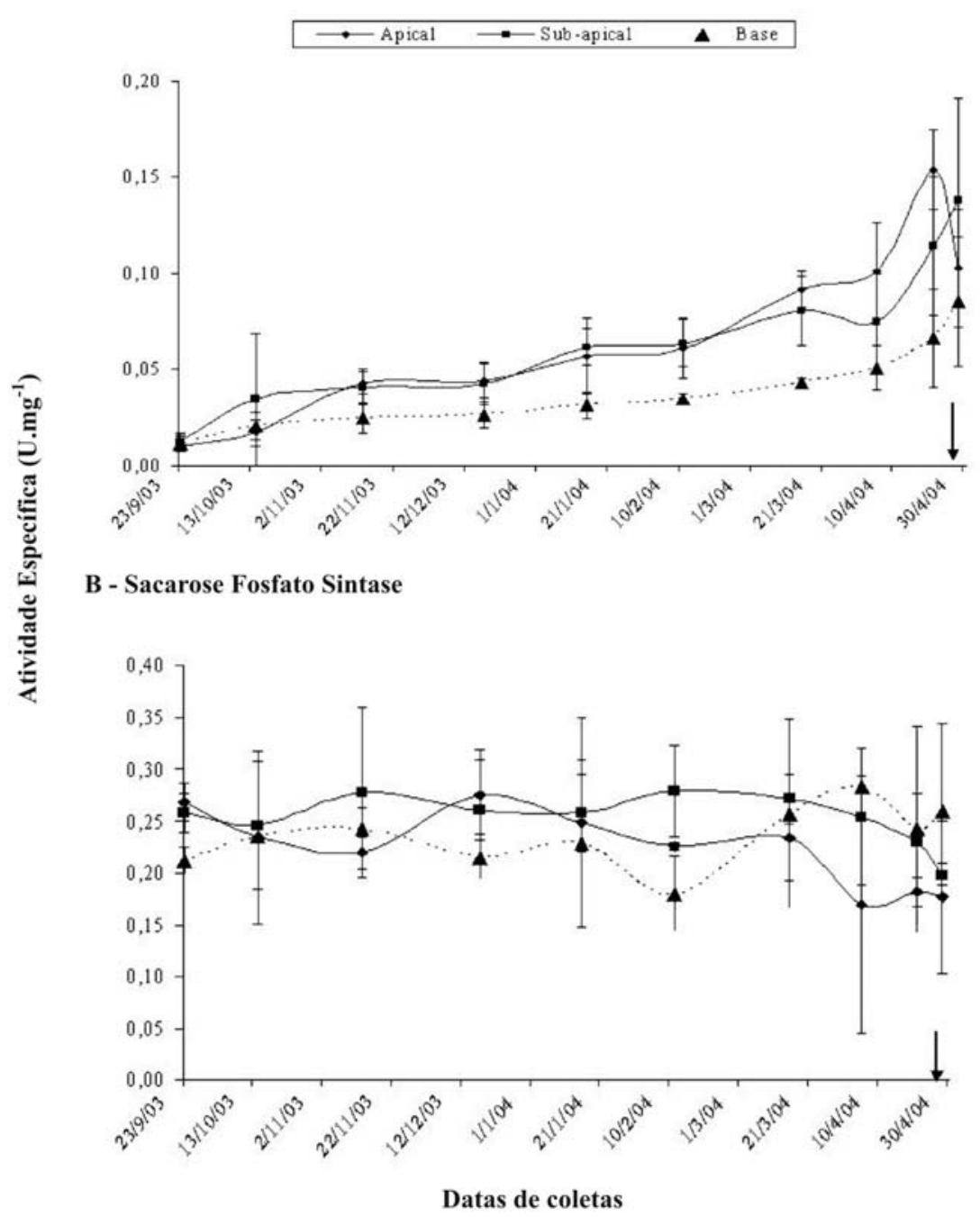

FIGURA 3 - Atividade da Alfa-amilase (A) e da Sacarose Fosfato Sintase - SPS (B) do lenho (xilema), de setembro a abril. A atividade enzimática foi mensurada para cada data de coleta, da porção lenhosa (xilema) nas posições apical, subapical e basal de ramos de nogueira. As barras indicam o desvio-padrão, e a seta, a data da primeira brotação (26-04). UMR/PIAF - ClermontFerrand, 2004.

\section{CONCLUSÕES}

1-Os resultados obtidos reforçam os resultados precedentes e indicam que o gradiente de brotação na nogueira se desenvolve durante a ecodormência e apresenta uma relação de dependência com a atividade da alfa-amilase.

2- Não está evidente a relação da atividade da sacarose fosfato sintese com a evolução do crescimento das gemas, durante a ecodormência.

\section{AGRADECIMENTOS}

À equipe francesa da Unidadade Mista de Pesquisa em Física e Fisiologia Integrada de Árvores frutíferas e Florestais (UMR-PIAF), pela acolhida e auxílio na execução dos trabalhos; aos coordenadores do projeto CAPES/COFECUB, no período: Dr. Flávio Gilberto Herter e Dr. Gilles Pétel; à Hervé Sinoquet e Jean-Louis Julien, Diretor e Diretor Adjunto da UMR-PIAF e, finalmente, agradecer à CAPES e ao Governo brasileiro, pela bolsa de estudos pós-doutoral concedida. 


\section{REFERÊNCIAS}

ALVES, G; DECOURTEIX, M.; FLEURAT-LESSARD, P.; SAKR S.; BONHOMME, M.; AMÉGLIO, T.; LACOINTE, A.; JULIEN, J.L.; PÉTEL, G; GUILLIOT, A. Spatial activity and expression of plasma membrane $\mathrm{H}^{+}$-ATPase in xylem of walnut tree (Juglans regia L.), during dormancy and growth resumption. Tree Physiology, Victoria, v.27, p.14711480, 2007.

AMEGLIO, T.; GUILLIOT, A.; LACOINTE, A.; JULIEN, J.L.; ALVES, G.; VALENTIN, V.;PETEL, G. Water relations in winter: effect on budbreak of walnut tree. In: VIEMONT, J.D.; CRABBE, J. (Ed.). Dormancy in plants, from whole plant behaviour to cellular control. Oxon (UK) : CABI, 2000. p. 109120.

AMÉGLIO, T.; EWERS, F.W.; COCHARD, H.; MARTIGNAC, M.; VANDAME, M.; BODET, C.; CRUIZIAT, P. Winter stem pressures in walnut trees: effects of carbohydrates, cooling and freezing. Tree Physiology, Victoria, v.21, p.384-394, 2001.

BRADFORD, M.M. A rapid and sensitive method for the quantization of microgram quantities of protein utilizing the principle of protein-dye binding. Analytical Biochemistry, New York, v.72, p.248-254, 1976.

BRUNEL, N. Étude du déterminisme de la préséance des bourgeons le long du rameau d'un an chez le pommier (Malus domestica [L.] Bork): Approches morphologique, biochimique et moléculaire. 2001. $212 \mathrm{f}$. Thèse (Doctorat) - Ecole Doctorale d'Angers. Université d'Angers, Angers, 2001.

CHAMPAGNAT, P. Quelques caractères de la ramification du rameau d'un an des végétaux ligneux. In: CONGRES POMOLOGIE, 96., 1965, France. Anais... p. 9-33.

CHAMPAGNAT, P. Rest and activity in vegetative buds of trees. Annales des Sciences Forestières, Paris, v. 46, p.9-26, 1989.

CRABBÉ, J. Aspects particuliers de la morphogenèse caulinaire des végétaux et introduction à leur étude quantitative. Gembloux: IRSIA, 1987.116p.

DECOURTEIX, M.; ALVES, A.; BONHOMME, M.; PEUCH, M.; BEN BAAZIZ, K.; BRUNEL, N.;
GUILLIOT,A.; RAGEAU, R.; AMÉGLIO, T.; PÉTEL, G.; SAKR, S. Sucrose (JrSUT1) and Hexoses (JrHT1 and 2) transporters in walnut xylem parenchyma cells: their potential role in early events of growth resumption. Tree Physiology, Victoria, v.28, p.215224, 2008.

ELLE, D.; SAUTER, J.J. Seasonal changes of activity of a starch granule bound endoamylase and of a starch phosphorylase in Poplar wood (Populus $\mathrm{x}$ canadensis Moench robusta) and their possible regulation by temperature and phytohormones. Journal of Plant Physiology, Jena, v.156, p.731-740, 2000.

HAUCH, S.; MAGEL, E. Extractable activities and protein content of sucrose-phosphate synthase, sucrose synthase and neutral invertase in trunk tissues of Robinia pseudoacacia L. are related to cambial wood production and heartwood formation. Planta, Berlin, v.207, p.266-274, 1998.

LACOINTE, A.; AMÉGLIO, T.; DAUDET, F.A.; FROSSARD, J.S.; SAINT-JOANIS, B.; VANDAME, M.; ADAM, B.; BODET, C.; CROCOMBETTE, M.; PLOQUIN, S.; DELÉENS, E.; LELARGE, C.; SONG, G.C. Short- and long- term carbon allocation in young walnut with two branches grown in different light environments: a 13C - 14C double tracing experiments. Acta Horticulturae, Wageningen, v.544, p.219-227, 2001.

LEFEVRE, S. Caractérisations biochimique et moléculaire de la mobilisation des réserves amylacées du xylème du noyer (Juglans regia) pendant la période non feuillée. 2002. 25 f. Memmoire de thèse (Diplome d'étude aprofondu en Physiologie et Génetique Moléculaires) - Université Blaise Pascal, Clermont-Ferrand, 2002.

LEITE, G. B. Evolution des états des bourgeons et de leur hétérogénéité le long du rameau d'un an de pêcher sous différents régimes de températures après l'installation de l'endodormance. 2004. $159 \mathrm{f}$. Thèse (Doctorat) - Ecole Doctorale des Sciences de la Vie et de la Santé, Université Blaise Pascal, Clermont-Ferrand, 2004.

MAUGET, J. Relation entre dormance et précocité de débourrement des bourgeons du noyer (Juglans regia L.): influence du génotype et du mileu. In: COLLOQUE SUR LES RECHERCHES FRUTIÈRES, 2., 1982, Bordeaux. Anais... Bordeaux: INRA, 1982. p.95-106. 
MAUGET, J. C. Comportement comparé des bourgeons de l'année et des bourgeons latents chez le noyer (Juglans regia L., cv. 'Franquette'). Conséquences sur la morphogenèse de l'arbre. Agronomie, Paris, v. 4, n .6, p.507-515, 1984.

MAUGET, J. C.; RAGEAU, R. Coup d'oeil sur les connaissances en physiologie de la ramification chez les ligneux. In: ANDRIEU B. (Ed.). Séminaire de Modélisation architecturale. Paris: INRA, Département de Bioclimatologie, 1997. p. 137-145.

MACGRANAHAN, G.; LESLIE, C. Walnuts (Juglans). In: MOORE, J.N.; BALLINGTON JUNIOR, J.R. Genetic resources of temperate fruit and nut crops. International Society of Horticultural Science, Mount Vernon, v.1, p.907-951, 1990.

RAGEAU, R. Croissance et débourrement des bourgeons végétatifs de Pêcher au cours d'un test classique de dormance. Comptes Rendus de l'Académie des Sciences, Série D, Paris, v.287, p.1119-1122, 1978.

ROITSCH, T. Source-sink regulation by sugar and stress. Current Opinion in Plant Biology, Amsterdam, v. 2, n.3, p.198-206, 1999.

SAUTER J.J. Temperature-induced changes in starch and sugars in the stem of Populus $x$ canadensis "robusta”. Journal of Plant Physiology, Jena, v.132, p.608-612, 1988.
SAUTER, J.J.; ELLE, D.; WITT, W. A starch granule bound endoamylase and its possible role during cold acclimation of parenchyma cells in poplar wood (Populus $x$ canadensis Moench robusta). Journal of Plant Physiology, Jena, v.153, p.739-744, 1998.

SCHRADER, S.; SAUTER, J.J. Seasonal changes of sucrose-phosphate synthase and sucrose synthase activities in poplar wood (Populus $\mathrm{x}$ canadensis Moench 'robusta') and their possible role in carbohydrate metabolim. Journal of Plant Physiology, Jena, v.8, p.833-843, 2002.

USDA. Walnuts: production, supply and distribution in selected countries, 1999. Disponivel em: <http:// www.fas.usda.gov/htp2/circular/1999/99-11/ walntpsd.pdf $>$. Acesso em: 10 nov. 2008

WEGRZYN, T.; REILLY, K.; MURPHY, P.; NEWCOMB, R.; GARDNER, R.; MACRAE, E. A novel alpha-amylase gene is trasiently upregulated during low temperature exposure in apple fruit. European Journal of Biochemistry, Oxford, v.267, p.1313-1322, 2000.

WITT, W.; SAUTER, J.J. Enzymes of starch metabolism in poplar wood during fall and winter. Journal of Plant Physiology, Jena, v.143, p.625-631, 1994. 